\title{
VISIÓN DEL HOMBRE LATINOAMERICANO Y LA IDEA DE EDUCACIÓN EN FERNANDO GONZÁLEZ OCHOA ${ }^{1}$
}

\author{
Diego Alejandro Rincón Rojas \\ Universidad Santo Tomás
}

\section{Resumen}

Del maestro Fernando González Ochoa se han dicho y escrito muchas cosas. Se le ha tildado de ateo, rebelde, mal hablado; pero se olvida que fue un místico que buscó llegar a una comunión con la Intimidad (Dios), un hombre amante de la vida; se olvida su labor de maestro de escuela que quiso formar hombres auténticos, sacándolos de su vida de rebaño y dándoles el lugar que se merecen. El presente trabajo tiene como objetivo, a partir de la lectura de algunas de sus obras, indagar sobre el pensamiento antropológico y educativo del maestro Fernando González Ochoa. Presento al lector al Fernando González que encontré a lo largo de mi lectura de sus obras y del diverso material consultado para este trabajo. He sido lo más fiel posible a su pensamiento, realizando una actividad hermenéutica en la que busco presentar la comprensión propia del autor ante el contexto que le tocó vivir, el cual le sirvió de pretexto para escribir sus textos.

\section{Palabras clave}

Fernando González Ochoa, filosofía latinoamericana, educación, antropología filosófica.

\footnotetext{
El presente artículo es una síntesis de la tesis de grado para la Maestría en Filosofía Latinoamericana, que lleva el mismo título.
} 


\begin{abstract}
About master Fernando González Ochoa there have been said many things. He has been called atheist, rebel, bad speaking guy, but it's forgotten that he was a mistic who looked for a comunity with the Intimacy (God), a lover of life; his labor as school teacher is also neglected, as is the fact that he wanted to form authentic men, taking them out from their flock life and putting them in their corresponding place. The present research work pretends to investigate, from the readings of some of his books, the anthropological and educational thought of master Fernando González Ochoa. Here I present to the reader the Fernando González Ochoa I found in my readings of his works and in the material I consulted for this paper. I've been as true as possible to his thought, and I have done a hermeneutic activity in which I pretend to show his self-comprehension about the life context in which he lived, context that served him as pretext to write his books.
\end{abstract}

\title{
Key words
}

Fernando González Ochoa, Latinamerican philosophy, Education, Philosophical anthropology.

\section{Introducción}

Para poder comprender la obra y el pensamiento de Fernando González Ochoa, hay que acercarse al maestro con disposición de escucha, de dejarse remover internamente $\mathrm{e}$ incluso de sentir hastío de nuestra condición de hombres vanidosos y copiadores de modelos ajenos. Como diría Ernesto Ochoa Moreno al hablar de la obra de Fernando

González:

Lo importante, para encontrarse con Fernando González, no es oír hablar de él, sino hundirse en la lectura de sus obras. Para quien se acerque desprevenidamente, esa lectura será un descubri- miento. Ahí, en sus libros, hay que abrevar para encontrar un mensaje de salvadora rebeldía, de autenticidad, de vitalidad, de emoción ante la vida, de búsqueda incansable de la verdad, de sinceramiento ante uno mismo, ante los demás, ante Dios².

La obra de Fernando González sólo puede comprenderse desde la arrolladora capacidad de pasión por la vida de su autor; su lucidez de pensamiento y análisis; su voluntad de sinceridad y desnuda inocencia.

Nuestro viaje a pie por el pensamiento del maestro González se ha hecho en cinco capítulos que se desarrollan de la siguiente manera:

2 Ernesto Ochoa Moreno, “De la rebeldía al éxtasis”, Revista Panorama (revista de las compañías Shell en Colombia) 27 (1994), p. 38. 


\section{Tras las huellas del maestro de otra parte}

La filosofía de Fernando González Ochoa sólo puede entenderse desde su drama vital, pues él no vivió para pensar y escribir, sino que, en razón de sus búsquedas y agonías personales, escribió y pensó lo que fue viviendo. Por eso, antes de entrar en el tema específico de esta investigación, haremos un recorrido por la vida del maestro González ${ }^{3}$.

En una casa de la "Calle con caño", distinguida con el número 15-44, nació el 24 de abril de 1895, en Envigado ${ }^{4}$, Fernando González Ochoa, hijo de don Daniel González ${ }^{5}$ Araujo, de profesión maestro de escuela, y de doña Pastora Ochoa ${ }^{6}$ Estrada. El 26 de abril del mismo año fue bautizado en la parroquia de Santa Gertrudis; sus padrinos fueron sus abuelos paternos Antonio González y Bárbara Arango. Fue el segundo en una familia de trece hijos; de estos sólo sobrevivieron seis: Alfonso, Fernando, Sofía, Graciela, Alberto y Ligia; los demás murieron estando muy pequeños.
En el Colegio de la Presentación, en Envigado, dirigido por la Hermanas de la Caridad, es donde Fernando aprendió sus primeras letras. Fue expulsado de este colegio porque, después de cumplir con un arresto, castigo impuesto por su maestra, la hermana Belén, les gritó desde la calle: “¡Hermanas cagonas!”. Sus padres, queriendo evitar otro insuceso, decidieron trasladarlo al Colegio de San Ignacio de Loyola de Medellín, regentado por los padres jesuitas, para que continuara allí sus estudios de primaria y secundaria. Esta es la época en la que recibirá toda una influencia intelectual profunda. El método riguroso, el arte de formar silogismos y los ejercicios espirituales, todo ello sirvió para ir moldeando el carácter y la agudeza del espíritu crítico de González.

Al terminar su cuarto año de bachillerato comienza a mostrar su inconformismo con la filosofía escolástica que aún se enseñaba, razón por la cual llegará a ser expulsado del Colegio. Un día, en clase de filosofía, se atrevió a negarle a su profesor, el padre Quirós, el primer principio filosófico aristotélico-

3 Para esta semblanza biográfica se utilizará como fuente el libro Fernando González, filósofo de la autenticidad, de Javier Henao Hidrón (Medellín: Universidad de Antioquia, 1988), quien conoció personalmente al maestro González en 1958, cuando éste regresó de su consulado en Europa (ver p. 13).

4 "De los enormes troncos de sus árboles que, utilizados a la manera de vigas, sirvieron para construir los primeros puentes sobre sendas quebradas, provino el sonoro nombre de Envigado. La parroquia fue erigida en 1775, año en que el gobernador de la provincia de Antioquia expidió el título respectivo. Antes de la fundación sus campos estaban ocupados por familias de origen español en su mayor parte, por algunos negros esclavos y por unos pocos mestizos; de modo que, para entonces, la raza indígena había desaparecido por completo (...). Envigado se encuentra al sur del valle que los aborígenes llamaron de Aburrá, descubierto en 1541 por Jerónimo Luis Tejelo, al mando de un grupo de treinta soldados. Enmarcado por los municipios de Medellín, Itaguí, Sabaneta, Caldas y El Retiro, está a 1580 metros sobre el nivel del mar y tiene una temperatura promedio de $20^{\circ}$ centígrados. Su territorio de $50 \mathrm{~km}$ cuadrados de superficie, es hasta tal punto fértil y de hermosos paisajes”. Henao Hidrón, Fernando González..., pp. 17-19.

5 "El apellido González (hijo de Gonzalo) fue traído a la provincia de Antioquia, hacia 1680, por el asturiano don Juan González de Noriega y posteriormente a Envigado, por don Esteban González”. Henao Hidrón, Fernando González..., p. 19.

6 "El árbol genealógico de este apellido se inicia con el español Lucas de Ochoa y López Alday, quien llegó a tierras antioqueñas en 1690. Del matrimonio de uno de sus hijos, Nicolás, con Ignacia Tirado Zapata, nació Lucas de Ochoa Tirado, conocido como el 'gran progenitor' por haber sido el padre de veinte hijos, nacidos de cuatro matrimonios: 1769, 1781, 1796 y 1800. Murió a los 90 años de edad”. Henao Hidrón, Fernando González..., pp. 19-20. 
tomista que dice que una cosa no puede ser y no ser al mismo tiempo ${ }^{7}$.

González inquiere sobre la comprobación de su verdad y llega al choque y la negación de todo el mundo mental basado en ese primer principio: "Cuando al reverendo Padre Quirós, le preguntábamos cómo se comprobaba la verdad del primer principio que nos daba, nos decía: ese es el primero, ese no se comprueba, desde entonces estamos perdidos (...) solos, irremediablemente solos" ${ }^{\text {. }}$. Igualmente nos lo recuerda Alberto Restrepo:

González parte de un sistema que se fundamenta en un principio que se aleja del método argumental que es su esencia y su contenido; y repudiándolo niega al Dios que es su principio y su objetivo y se sume inmensamente solo en búsqueda de la verdad: "yo negué a Dios y el primer principio y desde ese día siento a Dios y me estoy librando de lo que han vivido los hombres” (Negroides, 15) ${ }^{9}$.

El maestro contaba con dieciséis años cuando fue expulsado del Colegio. De regreso a su natal Envigado, continúa con el hábito de la lectura combinando el tema filosófico y el religioso. Por un lado lee a Nietzsche, Schopenhauer y Spinoza; por otro, lee de la Biblia el libro de los Proverbios, el
Eclesiastés y las obras místicas de Teresa de Jesús.

Transcurridos cuatro meses de estar en su casa, aparecen sus primeros artículos en el periódico La Organización, de Medellín, bajo el título de "Notas". Allí escribe sobre escepticismo, inteligencias mediocres y la verdad, entre otros temas. Se hace notoria su admiración por Nietzsche y Spinoza. Por esta época comienza a preparar su primer libro que llevará como título Pensamientos de un viejo y que será publicado en 1916, a la edad de veintiún años.

Luego de tres años de lecturas, búsqueda interior y gestación de su libro, decide reanudar sus estudios secundarios, e ingresa a la Universidad de Antioquia, donde recibe el grado de "bachiller en filosofía y letras" el 8 de febrero de 1917. Allí cursa posteriormente la carrera de derecho en la facultad de jurisprudencia y ciencias políticas. Obtiene su título de abogado el 14 de mayo de 1919.

La tesis de grado titulada "El derecho a no obedecer” levanta polémica. El jurado examinador exigió el cambio del nombre por uno más acorde al título profesional conferido; al mismo tiempo se le recomendó precisar los conceptos relacionados con las doctrinas del totalitarismo y el anarquismo tratados en

\footnotetext{
"El principio de contradicción de la filosofía aristotélico-tomista, dice: Una cosa no puede ser y no ser al mismo tiempo y en un mismo sentido. Sobre ese primer principio de contradicción, que en fin de cuentas es la formulación negativa del prior principio de identidad: Una cosa es lo que es, se estructura todo el sistema filosófico racional y fixista, aristotélico-tomista, que para el adolescente Fernando González parte de una incongruencia fundamental: construido como sistema de razón discursiva, se apoya sobre un primer principio cuya evidencia es indemostrable a través de la razón discursiva y debe ser aceptado como evidente por intuición. En el contexto de la filosofía tomista, la enunciación del primer principio ontológico y la afirmación de la existencia de Dios son equivalentes, ya que en Dios, perfecta unidad de idea y realidad, se identifican esencia y existencia, verdad y ser, por lo que la negación del primer principio filosófico conlleva la negación de la existencia de Dios”. Alberto Restrepo, Para leer a Fernando González (Medellín: Universidad Pontificia Bolivariana, 1997), p. 94; cf. pp. 390-398.

$8 \quad$ Fernando González, Viaje a pie, $2^{\mathrm{a}}$ ed. (Bogotá: Tercer Mundo, 1976) p. 67.

9 Alberto Restrepo, Testigos de mi pueblo (Medellín: Argemiro Salazar, 1978) p. 60.
} 
el trabajo. González cambió el nombre de su trabajo por uno más breve, "Una tesis"10, e introdujo las modificaciones respectivas. El presidente de tesis, Víctor Cock, reconoció en una carta fechada el 12 de abril de 1969 las capacidades de González y consideró el contenido del trabajo como una serie de conceptos de "valía incontestable”. La síntesis de "Una tesis" se puede expresar de la siguiente manera:

En la materia amorfa en que se formaron todos los mundos estaba latente el devenir de la tierra; en el primer movimiento estaban encerrados todos los movimientos sucesivos. ¡Ridícula pretensión creer que el más infeliz ciudadano pueda cambiar los destinos humanos! La misma armonía que reina en el movimiento de los cuerpos celestes, reina en los fenómenos económicos (...). A los que digan que la escuela liberal es una antigüedad les contestaré que los principios más modernos de la filosofía la protegen; que el socialismo de Estado, tan en auge ahora, no es sino una mistificación alemana, una forma de militarismo, una consecuencia de los grandes gastos que han hecho los estados europeos para sostener los arma- mentos. La prueba de ello está en que sólo los pensadores oficiales de Alemania han sido los propagadores del socialismo de Estado ${ }^{11}$.

La abogacía, orientada a la modalidad del litigio, fue esporádica en el abogado González; la abogacía no le apasionaba y menos en Colombia donde todo está reducido a la lucha por ganar pleitos. Recién egresado, trabajó en Medellín con los abogados Fernando Isaza y Gustavo Escobar, muy prestigiosos profesionales del derecho. Con el tiempo, aceptó el cargo de magistrado en el Tribunal Superior de Manizales en 1921. En Medellín fue Juez Segundo Civil del Circuito (1928-1931) y Juez de Rentas (finales de los años 30).

Ocupando su cargo de juez civil del circuito, en sus vacaciones de diciembre de 1928 a enero de 1929, concibe su obra Viaje a pie ${ }^{12}$.

Esta obra constituyó un hito en la literatura colombiana, por tener un género intermedio entre novela y pensamiento, difícil de catalogar. Chocaba en múltiples puntos con la mentalidad tradicional por aquellas verdades expresadas con sinceridad poco común entre los escritores de la época. Mientras reci-

10 "En el fondo es la defensa de una tesis: la escuela liberal -sobre todo la escuela liberal evolucionista- no es una antigualla, puesto que sigue siendo regida por las leyes naturales que presiden la vida del hombre. El socialismo de Estado, en cambio, resulta ser una mistificación alemana, una forma de militarismo”. Restrepo, Testigos..., p. 58.

11 Alberto Saldarriaga, De la parroquia al cosmos: los viajes de Fernando González (S.p.i), pp. 412-413.

12 "Estos dos filósofos aficionados -González y don Benjamín- metieron la cabeza en muchas durante su viaje por pueblos, montañas y planicies de Antioquia, Caldas y el Valle, desde el 21 de diciembre de 1928 hasta el 18 de enero de 1929, para que pudiera producirse ese libro intenso, vivencial, inteligente y original, fiel en todo a su proceso de gestación: Viaje a pie. Iniciado el recorrido con morrales y bordones en Medellín, prosiguió por El Retiro, La Ceja, Abejorral, Aguadas, Pácora, Salamina, Aranzazu, Neira, Manizales (ruta seguida por los colonizadores antioqueños del siglo XIX) y por la vía de Cali, terminó en Buenaventura (...). Amistad noble, sincera y profunda, fue la que unió a Fernando González y Benjamín Correa. Nació siendo aquél el juez éste su secretario. Pero por encima de esta circunstancia trivial, tuvieron en común el gusto por la filosofía existencia l, por el arte imaginero, por el sentido picaresco de la vida. Aficiones que compartieron, atraídos por la fuerza del espíritu jesuítico”. Saldarriaga, De la parroquia..., pp. 71-72. 
bía el anatema de la Curia de Medellín ${ }^{13}$, los críticos colombianos y extranjeros la acogían como una de las obras más originales escritas en muchos años.

"El libro carece de unidad temática, pues González reúne los pensamientos que le ofrece su viaje por los pueblos de Antioquia y Caldas, de filósofo peripatético, en diálogo con la naturaleza, con los hombres que encuentra y con su compañero de viaje, don Benjamín"14. En esta obra, la vida es sentimiento de plenitud y dominio, satisfacción sentida por la superación de los obstáculos, amor a la vida, amor a la juventud, amor al aire puro. La vida es energía, esfuerzo, egoencia, triunfo. Es lógico que en estas condiciones ya no le sirva de guía el filósofo de la noche y el dolor Arthur Schopenhauer ${ }^{15}$, cuya filosofía dominó con su pesimismo el ambiente de Pensamientos de un viejo. El nuevo filósofo, cuya influencia benéfica domina el nuevo periodo es Friedrich Nietzsche (nacido el 15 de octubre de 1844 en Röcken, Prusia; fallecido en Weimar el 25 de agosto de 1900). La presencia de Nietzsche en el maestro González es la que señala el camino del amor a la vida y a la lucha y que a su vez lo instigó a la búsqueda de Cristo, como lo expresa en su libro Mi Simón Bolívar:

Estuve leyendo la vida de Federico Nietzsche. Me entristece esta vida noble de un ser que buscaba el amor y el arte y sólo encontraba bajeza. Era muy bueno, muy alto, muy grande. Quien pueda ser amigo como él, es muy grande (...).

¿Odiaba a Cristo? No; era su gran amor. Así como su frase acerca de las mujeres y el látigo significaba que la mujer es sacrificio, madre, mártir, así mismo en sus palabras acerca de Jesucristo quiere condenar la psicología del cristianismo europeo, con sus curas, su debilidad femenina, su capitalismo burgués ${ }^{16,17}$.

Desde su juventud, el maestro González encontró en Nietzsche las pautas fundamentales de su metafísica y de su actitud existencial. Dentro de ellas podemos destacar:

El campo gnoseológico de González se articula con Nietzsche en el amor al cuerpo y el

13 "Su desfachatez y versatilidad no eran alimento para la Colombia de entonces. De ahí la actitud radical y extrema asumida por la jerarquía eclesiástica, al prohibir su lectura, arguyendo que los fundamentos de la religión y la moral son atacados con ideas evolucionistas y las personas y cosas santas con sarcasmos volterianos”. Saldarriaga, De la parroquia...,pp. 75-76.

14 Restrepo, Para leer...,p. 86.

15 Nació el 22 de febrero de 1788 en Danzig (actual Gdañsk, Polonia); falleció el 21 de septiembre de 1860 en Frankfurt del Main. Para Schopenhauer, la tragedia de la vida surge de la naturaleza de la voluntad, que incita al individuo sin cesar hacia la consecución de metas sucesivas, ninguna de las cuales puede proporcionar satisfacción permanente a la actividad infinita de la fuerza de la vida, o voluntad. Así, la voluntad lleva a la persona al dolor, remedio al sufrimiento y a la muerte; a un ciclo sin fin de nacimiento, muerte y renacimiento, y la actividad de la voluntad sólo puede ser llevada a un fin a través de una actitud de renuncia, en la que la razón gobierne la voluntad hasta el punto que cese de esforzarse.

Tuvo esta concepción del origen de la vida en la voluntad gracias a un planteamiento que partía de la concepción de la naturaleza de la conciencia como impulsora. Mostró una fuerte influencia budista en su metafísica y un logrado sincretismo de ideas budistas y cristianas en sus reflexiones éticas (tomado de Enciclopedia Microsoft Encarta 2003).

16 Fernando González, Mi Simón Bolívar, 3ª ed. (Medellín: Bedout, 1969), p. 133.

17 Sobre el tema de Nietzsche y su visión sobre Jesucristo, puede verse mi artículo "Nietzsche: La recuperación del tipo psicológico de Jesús”, Cuadernos de filosofía latinoamericana, 80-81 (2000), pp. 50-56. 
sentido de la tierra, que son las raíces del conocimiento mismo.

- Desde Nietzsche asume la vivencia de la desigualdad entre los hombres, generadora de la individualidad humana que consiste en una superación de sí mismo, a partir de la aceptación y vivencia de las propias pasiones, camino al Superhombre.

- Asume el sentido del hombre como viajero, camino a la liberación.

- La vivencia de la belleza como ansia de posesión amorosa.

- Crítica de la modernidad.

- Desde la ética y la metafísica nietzscheana, asume la liberación del “deber ser” para llegar a la inocencia creadora que es expresión del ser auténtico.

Nada negativo, nada impuesto a la vida propia y original. Necesitamos originalidad para el espíritu, porque lo único hermoso es la manifestación que brota de la esencia vital de cada uno. Después de este excitante libro, pero escandaloso para la mentalidad parroquiana, la opinión pública queda pendiente de un nuevo escrito de este Nietzsche criollo.

En concepto de los críticos de la obra gonzaleciana, entre los que se destaca Alberto Restrepo, se debe resaltar su trilogía: Viaje a pie, El hermafrodita dormido y Los negroides. De estos libros, el último sería el más filosófico de todos; en él se analizan nuestros complejos y sus causas, y además hacen ver sus remedios.
Es una filosofía de nuestra historia dependiente y de la posible cura: la autoexpresión latinoamericana. En esta obra afirma: "Creo firmemente que soy el filósofo de Suramérica; creo en la misión, me veo obligado a ser áspero y seré odiado, pero ¿podría cumplir mi deber con dulces vocablos?”18

En 1942, durante la presidencia de Alfonso López Pumarejo, es nombrado asesor jurídico de la Junta de Valoración del municipio de Medellín. Más tarde sale de allí y abre su oficina de abogado. En 1953 vuelve al consulado de Colombia en Rotterdam (Holanda) y en Bilbao (España).

En el año de 1955 se presentó un hecho importante en la vida del maestro González y fue su postulación para el Premio Nobel de Literatura; dicha postulación la hicieron el filósofo francés Jean Paul Sartre y el escritor norteamericano Thornton Wilder, ambos amigos de González. Pero la Academia Colombiana de la Lengua no dio una opinión favorable a la postulación por no reunir, según ella, los requisitos para dicho galardón:

Un colombiano, en 1955, candidato a la más significativa distinción que se confiere en el mundo de las letras, y postulado por dos ilustres escritores representativos de Europa y América, resultaba algo inusitado. Tan sorprendente -sobre todo para sus compatriotas-, que cuando la Real Academia Sueca de Ciencias solicitó su opinión a la Academia Colombiana de la Lengua, esta corporación conceptuó que González carecía de los méritos necesarios para aspirar al excelso galardón.

18 Fernando González, Los negroides, $3^{\mathrm{a}}$ ed. (Medellín: Bedout, 1973), p. 31. 
Presidida entonces por el padre Félix Restrepo, la Academia de la Lengua fue aún más lejos: sugirió el nombre del octogenario escritor y filólogo español Ramón Menéndez Pidal, por considerar que éste reunía los requisitos, para ella esenciales, de larga trayectoria y reconocida erudición ${ }^{19}$.

Luego de esta vida errante, González se refugia en su finca llamada Otraparte ${ }^{20}$. A la entrada de ésta hace colocar una verja de hierro con la siguiente inscripción latina: Cave canem seu domus dominum (cuidado con el perro, o sea, con el dueño de la casa). Allí escribe sus dos últimas obras: El libro de los viajes o de las presencias y La tragicomedia del padre Elías y Martina la velera.

De su refugio sale también correspondencia dirigida a un viejo amigo, el jesuita Antonio Restrepo, y a su vecino el abad Andrés Ripol, cuya amistad lo marca profundamente. A las pocas horas de la partida del benedictino, en la noche del 16 de febrero de 1964, tras sufrir un infarto ${ }^{21}$, a los 69 años de edad, al maestro González lo recogió el silencio:

Atrás quedaban 69 años de lucha, un puñado de libros llenos de vibración y de verdad, un camino solitario hacia la inti- midad y una enseñanza de vida para ser descubierta por quien se acerque sin prejuicios a sus obras (...).

Fue un "maestro de escuela" que escandalizó y al mismo tiempo abrió derroteros hacia la autenticidad. Lo condenaron por ateo y, no obstante, fue un místico. Escribió en una prosa limpia e innovadora, pero "para lectores lejanos"22.

\section{La búsqueda antropológica: hombre, ¿quién eres?}

Este capítulo es un recorrido por el itinerario antropológico del maestro González y su intención de adentrarse en lo profundo del hombre como ser que va más allá de la mera existencia en una historia y un espacio concretos y limitados. En González no encontramos una definición absoluta del hombre; no hallamos observaciones teóricas de manera filosófica, sino que a partir de la vivencia del hombre como ser material, pasional y fisiológico, se llega al hombre como hijo de Dios:

En la medida en que González fue clarificando su método, su metafísica y su

19 Henao Hidrón, Fernando González..., p. 209.

20 "La finca, con casa encerrada por plácidos jardines, en la que se destacaba un bello balcón colonial, llamada (en recuerdo de un silencioso y enigmático ciudadano germano que, hasta cuatro lustros atrás, había sido el propietario de esos terrenos) La Huerta del Alemán. Pero a partir del año siguiente sería conocida con el nombre de Otraparte, una forma directa de expresar el vivo contraste entre los intereses de la sociedad y ‘el mundo’ de un viajero del espíritu” (Henao Hidrón, Fernando González..., pp. 13-14). En una pequeña casa de tejas de zinc y paredes de bahareque que tenía junto a su huerta, vivió allí solitario durante varios años de las décadas del veinte y el treinta, un alemán llamado Salterio, al parecer refugiado de la Primera Guerra Mundial. Un día en que se movilizaba en un bus de escalera entre Envigado y Medellín, murió en accidente de tránsito con su cargamento de hortalizas” (Henao Hidrón, Fernando González..., p. 228).

21 "Un infarto cardiaco que lo trasladó definitivamente al verdadero Otraparte... o reino del silencio. Allí debió encontrarse con los amigos que llenaron casi todo su espacio vital: Jesucristo, Pablo de Tarso, Zaqueo, el Padre Elías, Nicodemus, San Ignacio, San Francisco, Bolívar, Estanislao, Carlosé y don Benjamín” (Henao Hidrón, Fernando González..., p. 234).

22 Ochoa Moreno, “De la rebeldía...”, p. 36 
filosofía del conocimiento, fue realizando su conciencia de comunión con $\mathrm{La}$ Realidad y clarificando, ampliando y profundizando su vivencia y su noción de hombre.

La antropología gonzaliana es un proceso dialéctico desde el hombre fisiológico-instintivo hasta el hombre espiritualcontemplativo, que González deviene viviendo sus experiencias de hombre fisiológico, mental y espiritual ${ }^{23}$.

\subsection{El hombre como unidad}

Aunque el hombre elabore antropologías dualistas en las que se oponen cuerpo y espíritu, no hay ningún tipo de contrariedad entre estos dos elementos; tanto cuerpo como espíritu constituyen una unidad integral en la que la carne manifiesta el espíritu y se confunde con él, y por razón de esa unidad el hombre es pasión y un poco de razón.

Es interesante observar aquí cómo el pensamiento antropológico del maestro González se ve influenciado por el espíritu paulino en el tema de la unidad del hombre. Bornkamm, hablando de Pablo y su concepción del hombre, expresa: “Todos esos conceptos y expresiones no se refieren a los elementos parciales, sino al hombre entero, aunque eventualmente bajo diversos aspectos”24.

Para Pablo, el hombre no tiene cuerpo sino que es cuerpo. La palabra ‘cuerpo’ designa al mismo hombre en cuanto hombre. El hombre es un ser finito orientado hacia lo infinito, pero amenazado por la finitud. En cuanto cuerpo, pasión y mente, el hombre es existencia sometida a las categorías de tiempo y espacio; en cuanto espíritu, es intimidad, nexo intemporal con Dios. Así, las categorías del hombre son temporalidad, espacialidad y eternidad.

Teniendo en cuenta las categorías anteriormente mencionadas, nos damos cuenta de que "los hombres se saben solidarios en su condición de criaturas, al no hallar memoria de no haberse hecho, ni poseer capacidad de permanecer, por sí mismos, en su ser”25.

Encontramos igualmente que el hombre es un ser paradójico y necesitado de salvación. ¿Qué significa que el hombre sea una paradoja? El hombre es el encuentro de dos realidades opuestas en un mismo lugar, por tanto es una paradoja.

El hombre por momentos se siente abrumado ante el peso de las fuerzas del mal, no sabiendo qué hacer y dominado por la desesperación. "Y el Mal no sólo es una cuestión moral. También es personal. Constituye una experiencia íntima que todos conocemos”26. Por tanto, el Mal es una opción que tenemos siempre. Allí encuentra el motivo de su carácter paradójico, porque desea la presencia del bien pero percibe con mayor vehemencia la presencia del mal (Cf. Romanos 7,15$)$.

En González aparece de manera clara este tema de la paradoja donde el hombre mismo es una contradicción que sólo resuelve la gracia de Cristo. En el Libro de los viajes o de las presencias (tercera parte) se desenvuelve una trama de ascensos y caídas, de aspiraciones a la Intimidad y rupturas con ella. El camino hacia Dios es para González un camino de contradicciones: "De cómo se as-

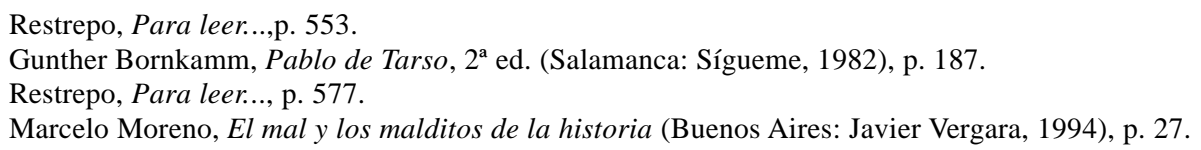


ciende en zig-zag. Amarguras. Contradicciones. Recaídas. Mayor ascenso" "27. En un proceso dialéctico se llega a una síntesis que es la salvación.

"El postulado básico que conforma la columna vertebral del pensamiento de González y de San Pablo (...) es que el hombre vive una situación desesperada y que busca salir de allí mediante instrumentos que están (...) más allá de la pura razón”28. Pablo afirma que los hombres estamos contenidos en Dios, y es allí donde se abre la posibilidad de salvación para la humanidad, "ya que en Él vivimos, nos movemos y existimos, como alguno de vuestros poetas ha dicho también: 'porque somos de su linaje'” (Hechos de los Apóstoles 17, 28).

El maestro González, inspirado en esta frase de Pablo, cree que el hombre es un ser que necesita salvación. Tomando esta cita, desarrolla una de sus ideas pilares: el hombre es un ser insignificante y conflictivo, pero cuya existencia está inmersa en Dios que lo abarca todo y que lo redime todo. Es un Dios que busca la salvación del hombre y la derrota del mal, pues "la victoria del Mal no sería otra cosa que la abolición de la historia -la brusca caída en el olvido- y su brutal reemplazo por la tristeza y la monotonía imbécil de las tinieblas" 29 .

Para González, el hombre es infinita posibilidad, es potencial real para ser otra cosa mejor; cuando el hombre empieza a descubrir en sí mismo el potencial que posee, estará en camino para su encuentro con la Presencia (Dios), habrá comenzado el viaje.
La afirmación de fondo es que el hombre es la criatura preferida de Dios, y esta posibilidad hace que seamos sus hijos, pues participamos de la naturaleza divina. Por eso Dios encarnó en uno de nosotros: "Si Dios se acercó a nosotros en Jesús, no fue por nuestros méritos, sino porque Él mismo así lo quiso por amor"30.

Como decía anteriormente, en el proceso dialéctico que se da en la vida del hombre, la salvación no se entiende sin el pecado. Pero González no entiende el pecado a la manera cristiana, asfixiada por el concepto de culpabilidad. Para él, el pecado es más bien la conciencia de la nada, la vivencia de la necesidad de ser salvado; por eso encuentra torpe pensar que la conciencia de pecado la inventó el cristianismo (posible discrepancia con Nietzsche): "Idiotas los que han dicho que la conciencia del pecado la inventó el cristianismo" ${ }^{\text {"31. }}$.

González quiere hacer aparecer esta sensación de un modo cósmico, queriendo significar con ello que tanto el hombre como la naturaleza sufren y hay en ellos un deseo de redención cósmica:

Porque la creación está aguardando en anhelante espera la manifestación de los hijos de Dios, ya que la creación fue sometida al fracaso, no por su propia voluntad, sino por el que la sometió, con la esperanza de que la creación será liberada de la esclavitud de la destrucción para ser admitida a la libertad gloriosa de los hijos de Dios (Romanos 8, 19-21).

27 Fernando González, Libro de los viajes o de las presencias, 2a ed. (Medellín: Bedout, 1973), p. 74.

28 Inés Ortiz, "Aproximaciones al pensamiento antropológico paulino en la obra de Fernando González" (monografía de grado, licenciatura en filosofía-religión, Universidad Santo Tomás, Bogotá, 1996), p. 84.

29 Moreno, El mal y los malditos..., p. 274.

30 Carlos Mesters, Pablo apóstol: Un trabajador que anuncia el Evangelio (Quito: Dei Verbum, 1994), p. 76.

31 González, Libro de los viajes..., p. 105. 
"El hombre debe esperar a que la salvación suceda, pues ésta se lleva a cabo en la vida cotidiana vivida con rectitud de intención. Esta convicción le hace decir a González citando a Pablo sin nombrarlo: 'porque este mundo no se acabará sino cuando todo lo cumplamos"”32. La condición previa para emprender el seguro viaje hacia Dios es que el hombre experimente que hay esperanza de ser salvado y que, por tanto, puede acceder al encuentro con Dios.

\subsection{El mestizo latinoamericano}

La tesis fundamental de González gira alrededor del hecho de que Suramérica ${ }^{33}$ es el escenario de una confluencia humana en el sentido de la mezcla de sangre indígena americana, blanca europea y negra africana ${ }^{34}$. Pero adentrándose un poco en las características sociopatológicas de estos grupos, encuentra que el blanco americano continúa siendo más bien europeo; el negro exhibe las peculiaridades inherentes a su condición de arribado. Estas diversas manifestaciones hacen que el blanco y el negro se encuentren desadaptados en el medio americano.

El blanco y el negro son extranjeros en este continente. El mulato, resultado de estas dos razas, "tiene la irritación meníngea del híbrido" 35 . De lo anterior se discierne el poco valor que González da al mulato; por eso llega a decir: "El mulato tiene la pereza del negro y la jactancia del blanco. El mulato no sirve (...)”36. Por tanto, el blanco y el negro son hombres deshabituados al medio americano, y en función de su mezcla también lo es el mulato. Haciendo un resumen de su frustración ante el hombre americano, González dirá:

Somos el compuesto abominable de esos tigres cazadores que vinieron a la América a derramarle su sangre y a encastar con las víctimas antes de sacrificarlas, para mezclar después los frutos espúreos de estos enlaces con el fruto de esos esclavos arrancados del África. Con tales mezclas, con tales elementos morales, ¿Cómo poner las leyes sobre los héroes y los principios sobre los hombres? ${ }^{37}$.

Es importante, en la constitución del futuro del hombre adaptado, la necesidad del hombre indígena ${ }^{38}$; al respecto, escribe González: "Un blanco no sirve en Suramérica; tampoco un negro; tampoco un mulato. Tiene que tener la sangre india en sus venas, porque ella es la aclimatada, ella es la que posee la sabiduría de nuestro continente" ${ }^{39}$. Su análisis es sociológicamente objetivo y se deriva de la noción fundamental de que el indio es el único ser humano adaptado al territorio

32 Ortiz, “Aproximaciones al pensamiento antropológico...”, p. 91.

33 Suramérica: término que emplea por razones de eufonía, pero en el cual incluye también a los países centroamericanos.

34 "El cruce ha sido arbitrario, al acaso, temerosos muchas veces, falto de sinceridad casi siempre, y en circunstancias de frecuente desigualdad, engaño y sometimiento. Descubridores y descubiertos; conquistadores y conquistados; colonizadores y colonizados; libres y esclavos (...). La fusión racial, tal como se ha presentado en el medio suramericano desde el descubrimiento, muestra resultados negativos; y cada una de las tres razas, aisladamente, ofrece también desventajas”. Henao Hidrón, Fernando González..., p. 163. (Cf. Restrepo, Para leer..., pp. 45-50).

35 Fernando González, Mi compadre, 3ª ed. (Medellín: Bedout, 1975), p. 131.

36 González, Mi compadre..., p. 65.

37 González, Mi compadre..., p. 34.

38 "Pero si conserva su esperanza Suramérica, ella es debida al indio. A su malicia, su reserva, la concentración dentro de sí mismo y la comunidad con las fuerzas elementales”. González, Mi compadre..., p. 164.

39 González, Mi compadre..., p. 70. 
americano. El indio es el remedio natural para la condición psico-socio-patológica de la inadaptación.

Simplificando sus análisis y utilizando porcentajes étnicos, González nos dirá que el verdadero hombre suramericano deberá estar conformado, o ser el producto de, un $45 \%$ de indio, un $45 \%$ de blanco y un $10 \%$ de negro (éste referido a la capacidad de impertinencia). Por tanto, "Suramérica es mestiza, sangres española e india con pinta negra" ${ }^{40}$.

Queda claro el sentimiento de esperanza referente al futuro del hombre americano; como diría Jorge Ordenes:

En la mezcla de sangres, la contribución indígena parece crucial en función a que es la única del ancestro americano eviterno (...) es pues la gran compenetración de sangres blanca, negra e indígena y sus actitudes y sentimientos de mancomunidad hereditaria que hará posible el gran mestizo americano como remedio al mal de la inadaptación ${ }^{41}$.

El gran mestizo americano está en gestación; el futuro nos pertenece en función de la promesa de la personalidad que llegará a manifestarse. Al respecto, nos dice González: "Suramérica es una raza en gestación; es el horno del hombre del futuro, patria de cosas nuevas" ${ }^{42}$.

El sueño de González es elevar la personalidad del mestizo a su expresión máxima de conciencia. En el proceso ascendente, los problemas de falta de personalidad quedarán rezagados.
Es llamativo ver que en escritos posteriores hay un escepticismo ante esta teoría del mestizo; para el maestro González es difícil que pueda darse este tipo de hombre. Así nos lo hace ver Javier Henao, cuando al respecto dice:

Lo cierto es que Fernando González no ocultó el escepticismo en relación con la validez de su teoría, a la cual dedicó algunos capítulos de Mi Simón Bolívar, Don Mirócletes y Mi compadre, lo cual significa que los postulados de la misma fueron expuestos entre 1930 y 1934. Pero en 1936, en Los negroides, si bien continuaba convencido de que con los elementos existentes en la Gran Colombia podía hacerse algo asombroso, reconocía que el destino más probable de los países suramericanos es la inmigración de europeos y asiáticos. Unos y otros están ahítos de estas tierras. Las necesitan para solucionar su problema de exceso de población y, simultáneamente, expandir su comercio.

Y en 1959, en el Libro de los viajes, admitía que el problema fundamental es que no aparecen individuos, nudos de individualidad, "ni siquiera de Marx y Lenin”. La conclusión era ya ostensiblemente pesimista: Todo es aquí exhalación, fucilazo. Sistemas nerviosos desarreglados por el bombardeo de influencias contradictorias. Decididamente, no habrá por aquí una original representación del Gran Mulato soñado ${ }^{43}$.

Vistas las cosas así, considero que la esperanza en este modelo de hombre ya no se

40 González, Mi compadre..., p. 14.

41 Jorge Ordenes, El ser moral en las obras de Fernando González (Medellín: Universidad de Antioquia, 1983), pp. 137-138.

$42 \quad$ González, Los negroides..., p. 106.

43 Henao Hidrón, Fernando González..., pp. 167-168. 
entenderá como una raza física visible, sino como actitud, comportamiento del hombre americano en relación a las otras razas y culturas. Es aquí donde aparece el planteamiento del hombre egoente, contrapuesto al hombre vanidoso (perjudicial para Suramérica).

\subsection{Vanidad - Egoencia}

En esta nueva etapa del maestro González se da la contraposición entre dos tipos de comportamiento; la Vanidad, tradicional en Suramérica, y la Egoencia, superación de la anterior. "Aquellos vocablos se predican de actos, individuos y pueblos, y sirven para calificar su grado de energía ${ }^{44}$, de fuerza vital, de autenticidad" ${ }^{45}$. Las siguientes son sus caracterizaciones:

\subsubsection{Vanidad $^{46}$}

- La vanidad o imitación es una "forma de simulación y hurto de cualidades" (Los negroides, aforismo 16).

- Es característica de la conciencia fisiológica.

- La vanidad es apariencia vacía: "Suramérica: vanidad. Copiadas constituciones, leyes y costumbres; la pedagogía, métodos y programas, copiados; copiadas todas las formas. Tienen vergüenza del carriel envigadeño y de la ruana. ¿Qué hay original? ¿Qué manifestación brota, así como el agua de la peña?” (Los negroides, aforismo 135).

- “Vanidad es vacío; egoencia es realidad. El vanidoso simula y sus manifestaciones o formas carecen de la gracia vital” (Los negrodes, aforismo 268).

- Todo acto vanidoso obedece a consideraciones sociales y no a determinaciones íntimas.

- El vanidoso tiene hipertrofiado el deseo de ser considerado socialmente, y su fin, por ende, es aparentar.

- “[González, ] al renegar de las cautelas, rechazó la apariencia como vestuario espiritual (...) por eso condena la vanidad: 'la vanidad está en razón inversa de la personalidad. Por eso, a medida que uno medita, que uno se cultiva, disminuye' (p. 11)”47.

- El hombre grancolombiano alimenta la diástole $^{48}$ de la vanidad. Con esta comparación se nos ilustra cómo el hombre se está dejando influenciar por lo ajeno a él, se llena con lo externo y no hay espacio para la originalidad, pues todo le viene de fuera y lo copia.

\subsubsection{Egoencia ${ }^{49}$}

- La egoencia o personalidad es la dedicación al cultivo de la expresión, evitando influencias que la desvirtúen.

44 "Observamos que una ordenación del pensamiento de González a este respecto debería introducirse con el postulado de que la energía esencial del universo tiende a algo en forma fisiológica continua (...) lo único hermoso es la manifestación que brota de la esencia vital de cada uno” (Ordenes, El ser moral..., pp. 2829).

45 Henao Hidrón, Fernando González..., p. 153.

46 Cf. Ordenes, El ser moral..., pp. 420-424.

47 Ordenes, El ser moral..., p. 214.

48 Fase del ritmo cardiaco en que se relaja el músculo y el corazón se llena nuevamente con la sangre proveniente de las venas.

49 Cf. Ordenes, El ser moral..., pp. 424-425. 
- Es el nivel cósmico de la conciencia.

- La egoencia o personalidad es la contraposición dialéctica a la vanidad.

- Se forma en un proceso original que conlleva a un ascenso espiritual hacia la conciencia cósmica.

- Para el egoente, su secreto está en la fuerza interna que derrama al exterior. Expresa vitalidad, todo lo embellece.

- “Nosotros podríamos identificar a la personalidad y a la vanidad como atributos de conciencia; aquél inherente a un estado de conciencia elevada, éste a la condición fisiológica donde la energía busca organizarse metódicamente" ${ }^{50}$.

- El afán didáctico de González, con respecto al desarrollo de la personalidad como elemento antídoto a la vanidad, hace que hable de la educación del niño en la verdad: 'toda ley que se enseña a un niño sin que la haya vivido, descubierto en sí mismo, es vanidad' (p.18)”51.

- El egoente es honesto consigo mismo, rechaza toda apariencia como propia o exhibida por otros.

- "El egoente, haga lo que hiciere, tiene la gracia de la lógica; haga lo que hiciere, ya vaya roto o sucio, nos enamora, porque la vida es lo que nos subyuga” (Los negroides, aforismo 268).
- El hombre egoente es la sístole ${ }^{52}$ de la egoencia o personalidad. Con esta comparación, González nos quiere mostrar cómo el hombre debe buscar dentro de sí mismo su autenticidad y sacar a la luz, en un proceso mayéutico, todos los valores que posee y que lo hacen original y no repetidor de conceptos y modelos.

Luego de esta breve caracterización, podemos concluir este capítulo diciendo que el hombre egoente es el prototipo superador de la vanidad y todas sus consecuencias. Es el hombre original, creador, con conciencia cósmica, amante de la vida:

Concordemos pues que la personalidad, como antítesis de la vanidad, viene a ser característica del proceso ascendente de conciencia. La personalidad plena, la conciencia cósmica, se encontrará una vez que toda apariencia desaparezca. Dios será presencia plena. El hombre está en el mundo para manifestarse a través de la digestión y conocimiento de su circunstancia vital. La obligación será llegar a la conciencia plena ${ }^{53}$.

\section{Pensamiento educativo gonzaleciano}

Fernando González aspiraba a que el hombre, al educarse, llegara a un desarrollo de la inteligencia, de la personalidad, de la con-

\footnotetext{
Ordenes, El ser moral..., p. 208.

Ordenes, El ser moral..., p. 214.

Movimiento de contracción del corazón y las arterias, para empujar la sangre que contienen.

Ordenes, El ser moral..., p. 221.
} 
ciencia, basado en los principios científicos para que el resultado no fallara.

El maestro González no descuidó el tema de la educación, sino que siempre lo tuvo presente en sus obras ${ }^{54}$, no sólo para darle aportes, sino para criticarlo cuando no contribuía en nada a la vida del alumno y de la sociedad, coincidiendo en su pensamiento con Jean Jacques Rousseau. El filósofo francés, al hablar de la educación y el maestro, dice: "En lugar de hacernos buscar las demostraciones, se nos dictan; en lugar de enseñarnos a razonar, razonan por nosotros, el profesor ya no ejercita nada más que nuestra memoria" ${ }^{55}$. En consonancia con ello, González expresa:

Es preciso que la escuela sea creadora en vez de enseñadora. Que los maestros no enseñen a los niños, sino que los instiguen a la manifestación (...). El maestro verdadero no enseña a resolver los problemas matemáticos, sino que instiga hacia la solución individual. El mejor método es el que cada uno tiene dentro. He ensayado con tres niños, y los tres han llegado a la solución por tres caminos (Los negroides, aforismo 150).

El secreto del progreso para la Nación está en el maestro de escuela, el que enseña a los niños a creer en sí mismos, en sus fuerzas, a hacerse sensibles al orgullo racial y al sentimiento de su propia expresión:
Necesitamos hombres que... ¡inventen, actúen, realicen niños colombianos! ¡No tomen prestado, no reciban regalos, no pidan! ¡Qué vergüenza es hoy nuestra pobre patria! En tiempo del Libertador, imponían al mundo sus conceptos de libertad y de gloria. Pero, ya murió Simón, y debo contentarme ante el recuerdo de Páez y el Mayor Santander, conciencias orgánicas ${ }^{56}$.

Como vemos, la misión del maestro es decisiva y delicada, si se piensa verdaderamente en el fruto que se quiere tener. A su vez, González entendía que la política educativa colombiana era hábilmente manejada por personas que tenían intereses opuestos a los colombianos, y el maestro era uno de sus instrumentos.

Sin embargo, hace caer en cuenta que el maestro no debe marginarse, sino que debe luchar contra la ignorancia para superarse y cumplir con sus funciones y deberes. En cuanto a sus deberes, pretendía que tuviera presente, primero que todo, que trabajaba con el material humano más rico de los pueblos: la niñez y la juventud.

\subsection{Los dos maestros de escuela}

En su trabajo de reflexión sobre la educación, González descubre la existencia de dos tipos de maestros de escuela, que generan dos tipos de hombre y dos tipos de escuela totalmente opuestos. Estos tipos son:

54 "En 1937 insinuaba la urgente necesidad de una campaña contra esa costumbre que conduce al vicio de la repetición mecánica de cosas leídas. Sugería, en su reemplazo, instigar a la investigación, a la experimentación, a la documentación personal; organizar excursiones a pie con objeto científico: formar herbarios, coleccionar piedras y animales. Advertía que aquella lectura suele generar una clase muy peculiar de genios. Son los 'genios de las nalgas' (capacidad de sentarse a copiar)”. Henao Hidrón, Fernando González..., p. 157.

55 Jean Jacques Rousseau, El Emilio (S.p.i), p. 82.

56 Gonzalez, Mi Simón Bolívar..., p. 112. 


\begin{tabular}{|c|c|}
\hline \multicolumn{2}{|c|}{ MAESTRO REPETIDOR } \\
\hline FUNCIÓN & $\begin{array}{l}\text { Este maestro se dedica a repetir conceptos } \\
\text { ajenos }\end{array}$ \\
\hline MÉTODO & $\begin{array}{l}\text { Procura el crecimiento de afuera hacia } \\
\text { adentro }\end{array}$ \\
\hline FINALIDAD & Ilustración y sumisión al orden establecido \\
\hline RESULTADO & $\begin{array}{l}\text { Un hombre imitador, vanidoso, que se ajus- } \\
\text { ta a normas y conceptos }\end{array}$ \\
\hline ESCUELA & La escuela de Educación \\
\hline CITA DE FERNANDO GONZÁLEZ & $\begin{array}{l}\text { "Educar es formar a los hombres conforme } \\
\text { a modelo (éste es la verdad, la personalidad } \\
\text { del genio). Hombre educado significa el que } \\
\text { se ajusta a las normas. El tipo de hombre } \\
\text { educado es igual al perro sabio"57. }\end{array}$ \\
\hline \multicolumn{2}{|c|}{ MAESTRO INSTIGADOR } \\
\hline FUNCIÓN & $\begin{array}{l}\text { Este maestro se dedica a instigar (impulsar) } \\
\text { la personalidad del educando }\end{array}$ \\
\hline MÉTODO & Cultivar el crecimiento de adentro hacia fuera \\
\hline FINALIDAD & La autoexpresión \\
\hline RESULTADO & El hombre egoente y creador \\
\hline ESCUELA & La escuela de la cultura ${ }^{58}$ \\
\hline CITA DE FERNANDO GONZÁLEZ & $\begin{array}{l}\text { "El secreto del progreso para Colombia está } \\
\text { en el maestro de escuela que enseña a los } \\
\text { niños a creer en sí mismos, en sus fuerzas; } \\
\text { hacerlos sensibles al orgullo racial y al sen- } \\
\text { timiento de propia expresión"59. }\end{array}$ \\
\hline
\end{tabular}

57 Fernando González, Cartas a Estanislao, 2ª ed. (Medellín: Bedout, 1970), p. 97.

58 En González, la palabra cultura tiene un sentido positivo y liberador de energías que permiten al hombre llegar a autoexpresarse: "la cultura consiste en desnudarnos, en abandonar lo simulado, lo ajeno, lo que nos viene de fuera, y en autoexpresarnos" (Los negroides, aforismo 270). Es manera colectiva de pensar y de sentir, conjunto de costumbres e instituciones; todo ello es efecto y el medio de una cultura personal de todos aquellos que pertenecen a ese medio.

59 González, Mi Simón Bolívar..., p. 132. 
González rechazó el método didáctico-educador, de la Escuela de la Educación y del maestro ilustrador, y optó por el método creador, de la Escuela de la Cultura y del maestro instigador y padre espiritual que ayuda a parir. Por tanto, hay que trabajar de adentro hacia afuera, hay que ser maestro y padre en el proceso educativo. Así nos lo hace ver en los siguientes aforismos de Los negroides:

- "Pedagogo es quien comprende, no quien enseña letanías” (aforismo 145).

- "Hasta hoy ha imperado el rebaño, la educación; están próximos ya los tiempos de la cultura, la auto-expresión. Está llegando el tiempo de la libertad" (aforismo 146).

- "Secreto interesante es el de entender que cada uno necesita de maestro. En todo caso, saber que sois individualidades y que si os perdéis en el montón es por no haberos conocido, por carecer de maestro apropiado que os haya servido de bordón y acicate” (aforismo 209).

El propósito de González es lograr la transformación del sistema educativo para propiciar el paso del rebaño a la libertad, para que el hombre trascienda en su conciencia y su conocimiento. En esta forma se van rompiendo los moldes de la escuela tradicional que educa pero que no prepara al hombre para la vida real ni satisface las necesidades reales del país: "Es cierto que se aprende estudiando, pero se aprende mal y nada acerca de los hombres y de la vida. Se aprenden enumeraciones; la vida es preciso vivirla"60.

La educación de la personalidad es aquella que debe guiar la conducta del hombre, de manera que redunde en un proceder natural y original, alejado de la vanidad que deriva de la imitación, del complejo de inferioridad y de la pereza del alma: "Adquirir personalidad es, ante todo, disciplinarse mediante prácticas que conduzcan al conocimiento de sí mismo. Este conocimiento es esencial y la fuente de los demás conocimientos”61.

\section{La autenticidad: pilar de la educación}

Los discursos sobre la formación humana actualmente se encuentran influenciados por los lineamientos de un proyecto que aún permanece aferrado a las pretensiones utilitaristas de una modernidad unidimensional. Hasta ahora la teoría de la formación no ha podido desligarse de la primacía dada al funcionamiento de la razón y la observación.

Desde esta perspectiva se concibe el desarrollo humano como un proceso constante de ascenso hacia estados de perfección que siguen una linealidad orientada por la idea de progreso, donde se valora el alcance de lo "más avanzado" o lo "más cercano" al final del proceso. De igual manera, se da una absolutización de las pretensiones de la educación en y para la razón.

Las expresiones más propias de una conciencia autónoma e individual del hombre ilustrado, según esta perspectiva, serán realización racional, intención consciente y claridad conceptual. Esto se ha venido convirtiendo en el fin más alto que debe lograr toda labor educativa. Queda flotando en el ambiente la pregunta: ¿cómo volver a una visión del hombre original que trascienda los parámetros de la razón y permita desarrollar una formación integral?

\footnotetext{
60 González, Mi Simón Bolívar..., p. 102.

61 Henao Hidrón, Fernando González...,p. 158.
} 
En este punto, y buscando una respuesta al anterior interrogante, se recurre al pensamiento de nuestro filósofo colombiano y se propone la noción de autenticidad como una valiosa contribución a la reflexión educativa. La autenticidad (categoría fundamental en el pensamiento gonzaleciano) nos permite darle un enfoque nuevo a la formación y nos lleva más allá de los simples márgenes de la razón.

La autenticidad, en palabras del maestro Fernando González, es la posibilidad de que "cada uno viva su experiencia y consuma sus instintos. La verdadera obra (la obra auténtica) está en vivir nuestra vida, en manifestarnos, en autoexpresarnos (...). El objetivo de la vida es que el individuo se autoexprese (...). El último fin de toda actividad debe ser el individuo"62.

Este concepto ocupa un lugar importante en su pensamiento y dentro de lo que él llamó filosofía de la personalidad. "La personalidad es conjunto de modos propios de manifestarse el individuo; la individualidad en cuanto aparecida o manifestada. Con este fin es imprescindible el empleo de métodos, los cuales conforman la cultura"63. En esta propuesta vital-existencial se entiende la autenticidad como la forma más propia de expresión del hombre, como la creación del sentido de la propia vida. La autenticidad está así opuesta a la vanidad y la simulación, que se convierten en obstáculos para un ascenso hacia la cultura y hacia el hombre egoente.
Adquirir personalidad es, ante todo, disciplinarse mediante prácticas que conduzcan al conocimiento propio. Este autoconocimiento es la fuente de los demás conocimientos. En ese vivir, buscar, conocer, aplica su método de Atisba y Escucha ${ }^{64}$; método que es "auscultación, conocimiento de sí y enfrentamiento consigo mismo, a la atisba y escucha, o sea, en convivencia con las manifestaciones de la vida” ${ }^{\circ 5}$.

El hombre asciende al liberarse de las tiranías que lo sujetan, en este caso de la tiranía de una educación de rebaño; el conocimiento es el camino de la liberación del hombre; la verdad es la libertad en acción: "la única libertad está en el entendimiento. El único método para liberarse es comprender. Sólo el espíritu es libre"66. Este proceso de liberación se va convirtiendo en un fenómeno moral de mejoramiento por medio de la búsqueda de un ideal al cual se tiende, en este caso, la autenticidad.

La educación enfocada hacia lo humano debe buscar el ser auténtico del hombre partiendo de su realidad, del mundo y de la vida en conjunto; esto implica una práctica auténtica del propio ser personal y plantea la búsqueda de nuevos caminos para la tradición educativa:

Una educación para (...) asumir una conciencia provocadora que le permita al otro dotar de sentido su propia existencia para que vaya más allá de lo puramente teóri-

62 Fernando González, Los negroides. Citado por Jesús Sánchez, “Autenticidad: Una mirada a la formación humana desde la obra de Fernando González”, El Colombiano (1º de diciembre de 1996), p. 11.

63 Henao Hidrón, Fernando González..., p. 158.

64 "Atisbador hemos llamado a este neosocrático. Hizo del transitivo atisbar -mirar con cuidado- su oficio predilecto, practicándolo primero consigo mismo y después con cuanto le rodeaba. Ambas direcciones lo condujeron a un mismo camino: el de la afirmación del yo. Sólo posible mediante el cultivo de la personalidad”. Henao Hidrón, Fernando González..., p. 158.

65 Restrepo, Para leer..., p. 291.

66 Fernando González, Antioquia (Medellín: Universidad de Antioquia, 1997), p. 341. 
co o material; de que se supere la noción extática de naturaleza humana y se la considere más bien como posibilidad siempre abierta del ser humano y de su auténtico esfuerzo creador”67.

Ser auténtico implica ir hacia el punto donde se origina todo lo que tiene sentido para mí, se trata de que lo que yo vivo posea validez y significación en mi formación integral. La autenticidad no es una negación de la racionalidad, sino la posibilidad de experimentarnos como totalidad: hombres que piensan, sienten y quieren. Es una concepción del hombre como existencia que trasciende y le da sentido a su devenir como superación, como libertad, como iniciativa y originalidad.

La norma general de conducta será meditar y crear. Con ello se insinúa la urgente necesidad de una campaña contra el vicio de la repetición mecánica de cosas leídas. Quiere, en su reemplazo, instigar a la investigación, a la experimentación, a la documentación personal; organizar excursiones a pie con objeto científico; formar herbarios, coleccionar piedras y animales.

Ahí esta planteado el camino de Fernando González. No es rebeldía sino búsqueda de la verdad, de la autenticidad. El maestro Fernando González fue eso, un maestro de escuela que enseña autenticidad, y para ello todo lo destruye, porque todo es mentira; todo cae bajo su crítica, áspera pero necesaria.

\section{Educar en la personalización}

En la perspectiva educativa gonzaleciana, le corresponde al maestro la noble tarea de llevar a sus estudiantes al conocimiento de la verdad. Él es quien inicia procesos y no puede ahorrar esfuerzos para que cada uno de los hombres y mujeres que se le han confiado conozca su ser espiritual, sociopolítico, profesional y comunicativo. Por tanto, la escuela es el lugar privilegiado para que la persona le de sentido a su vida, para que construya su proyecto de vida y se integre a la cultura; como diría el maestro González:

A mis jóvenes les ofrezco la cultura. Los haré dueños de los métodos, de sí mismos. Sus personalidades serán sus instrumentos. Los honores les vendrán de dentro para afuera. En una palabra, serán cultos, dueños de todo, porque poseerán el método. Sus cuerpos y sentimientos les obedecerán como autómatas ${ }^{68}$.

El educador es el facilitador del encuentro de la persona con su propio yo a través de su historia personal y por medio de una educación en la egoencia, la desvergüenza que quiere formar hombres libres, capaces y responsables al ejercer su autonomía.

El propósito de toda educación debe ser: humanizar y personalizar al hombre; nadie es persona realizada si no tiende a la personalización, a su autonomía, hacia los otros, hacia el mundo. Humanizar y personalizar significa que se asume un modelo concreto de hombre, un proyecto antropológico que debe estar en la base de la acción educativa humanizante y personalizante, que según hemos visto es el Hombre Egoente (amante de la vida, original, superador de la vanidad).

La meta a la que debe tender este proceso es la educación integral que desarrolle en el hombre su pensamiento y su libertad, que lo lleve a la formación de hábitos de compren-

67 Sánchez, “Autenticidad...”, p. 11.

${ }_{68}$ Fernando González, El remordimiento, 2 ed. (Medellín: Albón, 1969), p. 55. 
sión y comunión con la totalidad de la realidad en la cual humaniza su mundo, produce cultura, transforma la sociedad y construye la historia.

Es importante recuperar la confianza en la fuerza y eficacia de la educación en orden a la personalización, humanización y liberación del hombre mismo, no exclusivamente la parte racional, porque una educación en la que se prescinda del humanismo es una educación que se queda trunca y será desquiciada y desequilibrada.

Para González la escuela disciplinaria, en la convivencia con la naturaleza y con los maestros instigadores, genera hombres libres en la inocencia y la felicidad orgánica: "mi programa es escuelas disciplinarias al aire libre; hombres bellos (maestros) que den su belleza a los niños”69.

La educación, en el maestro González, tiene como objetivo reemplazar al hombre vanidoso (hombre del rebaño) por el hombre egoente, quien, a partir de creer en sí mismo, en sus posibilidades, puede lograr el cambio que tanto necesita la sociedad; para que deje de ser un "copietas” y sea un creador, un desvergonzado que no siente compasión de sí, que no reniega de lo que es, suramericano; que no vive bajo el yugo que los vanidosos imponen al rebaño, formado por la educación tradicional. Por ello, aboga por una educación y una cultura que desprecie la apariencia, lo vano; y que defienda la energía formulada a través del método que emocionalmente conduzca a desarrollar esa autoexpresión: "la cultura consiste en desnudarse, en abandonar lo simulado, lo ajeno, lo que nos viene de fuera, y en auto-expresarse" ${ }^{\text {"70 }}$.
Quisiera concluir este trabajo presentando, a manera de resumen de lo aquí tratado, una semblanza de la vida y obra del maestro González. Para ello, he extractado de Javier Henao Hidrón algunos apartes. A la pregunta “¿quién fue Fernando González Ochoa?”, se puede responder:

[Un hombre que] se atrevió a romper con la tendencia colombiana a la imitación, la formulación de ideas desprovistas de profundidad conceptual (que por lo tanto no son ideas sino opiniones), la investigación sin contacto con la realidad y la carencia de proyección hacia el futuro; mientras, simultáneamente, empleaba un lenguaje limpio, claro y directo, ausente de metáforas y de construcciones barrocas.

En vez de los temas abstractos o de las divagaciones eruditas, prefirió siempre el estudio de los problemas concretos. Primeramente los relacionados con su propio yo individual (...). Después abordó aspectos fundamentales de la realidad colombiana y, posteriormente, penetró en la sociología y psicología del hombre suramericano (...).

Para medir a sus personajes inventó el metro psíquico o concienciámetro, cuya escala más alta está representada por la conciencia cósmica, a la cual han logrado llegar algunos seres privilegiados (santos o sabios) que incorporaron el universo a su propio yo (...). De ahí su propuesta de una pedagogía de la cultura, concebida de dentro para fuera, con el fin de elevar el nivel de conciencia de los individuos y la motivación de los pueblos (...).

69 González, Cartas a Estanislao..., p. 203.

70 González, Los negroides..., p. 12. 
Su lema padezco, pero medito sirve para comprender cuál fue la dimensión de su lucha interior, tan solitaria y prolongada. Y de qué modo sacrificaba, a favor del entendimiento, las posibilidades de caer en el facilismo, en la atracción del halago, o en la mentira.

Por ese camino intimista y de desprecio por la mentira encontró su verdad ${ }^{71}$.

Este es nuestro maestro de Otraparte; este su pensamiento, revolucionario e inadecuado para sus contemporáneos de inicios del siglo XX pero iluminador para nosotros en los inicios del siglo XXI. Y, como lo dijera Nietzsche (el otro gran maestro incomprendido), ;el resto se sigue de ahí!

\section{Conclusión}

Con el anterior recorrido se quiere acercar al lector a una comprensión lo más clara posible sobre el tema del hombre y la educación en el maestro Fernando González. No pretende ser la última palabra sobre estos temas, pero sí servir de orientación para una lectura más cercana de la obra gonzaleciana.

Culmino esta síntesis con las palabras de María Helena Uribe, quien habla sobre los diversos lectores de la obra del maestro González y las variadas imágenes que de él quedan en la mente del lector:

Reunidos en torno a su vida y a su obra literaria permanecemos separados los unos de los otros frente a sus libros y frente a la vida misma de este ser multifacético. Cuando hablamos con distintas personas, podemos observar cómo cada una se aferra a su Fernando González. Nadie quiere que le maten el que conoció, amó o admiró. Algunos hasta se niegan a olvidar lo que en él odiaron. Así, en vida o en muerte, en muerte o en vida, según los diversos puntos de vista, Fernando sigue siendo el hombre de las controversias ${ }^{72}$.

71 Henao Hidrón, Fernando González..., pp. 240-242.

72 María Helena Uribe de Estrada, “El camino del amor en Fernando González”, Revista Universidad Pontificia Bolivariana 45.141 (1996), p. 156. 